Revista

Ibero-Americana

de Estratégıa
DOI: http://dx.doi.org/10.5585/riae.v11i1.1815

Organização: Comitê Científico Interinstitucional

Editor Científico: Benny Kramer Costa

Avaliação: Double Blind Review pelo SEER/OJS

Revisão: Gramatical, normativa e de formatação

\title{
COMPARAÇÃO DA GERAÇÃO DE VALOR ENTRE AS ESTRATÉGIAS PLANEJADAS E AS ESTRATÉGIAS EMERGENTES: UM ESTUDO BASEADO EM JOGOS DE EMPRESAS
}

\section{COMPARISON OF VALUE GENERATION STRATEGIES BETWEEN PLANNED AND EMERGING STRATEGIES: A STUDY BASED ON GAMES OF COMPANIES}

COMPARACIÓN DE LA GENERACIÓN DE VALOR ENTRE ESTRATEGIAS PLANIFICADASY LAS EMERGENTES: UN ESTUDIO BASADO EN JUEGOS DE EMPRESAS

\section{Marcos Paixão Garcez}

Doutor em Administração pela Universidade de São Paulo - USP

Professor do Programa de Mestrado Profissional em Administração - Gestão de Projetos da Universidade de São Paulo - PMPA-GP/UNINOVE

E-mail: mpgarcez@uninove.br (Brasil)

\section{Antonio Carlos Aidar Sauaia}

Doutor em Administração pela Universidade de São Paulo - USP

Professor da Universidade de São Paulo - USP

E-mail: asauaia@usp.br (Brasil) 
Comparação da Geração de Valor entre as Estratégias Planejadas e as Estratégias Emergentes: Um

Estudo Baseado em Jogos de Empresas

\section{COMPARAÇÃO DA GERAÇÃO DE VALOR ENTRE AS ESTRATÉGIAS PLANEJADAS E AS ESTRATÉGIAS EMERGENTES: UM ESTUDO BASEADO EM JOGOS DE EMPRESAS}

\section{RESUMO}

Investigam-se no presente estudo os efeitos econômicos das estratégias emergentes comparadas às estratégias planejadas na tomada de decisão e seus resultados diferenciais. Utilizaram-se como referenciais da pesquisa as escolas estratégicas, as tipologias de estratégias classificadas por Mintzberg, uma análise sobre competição em mercados e o uso de jogos de empresas como simuladores da realidade empresarial e método de pesquisa. No experimento controlado, os resultados do simulador EGS nas duas situações estudadas de tomada de decisões indicaram que as estratégias planejadas propiciaram agregação de valor para a indústria $(\mathrm{TIR}=1,51 \%)$ superior às estratégias emergentes em três períodos, nas quais a agregação de valor ocorreu em menores níveis (TIR $=1,40 \%$ ). Comparando-se as duas situações percebe-se a diferença de 7,9\% de valor em favor da situação planejada, sugerindo que a competição estabelecida na situação competitiva emergente tenha sido responsável pela menor agregação de valor nessa indústria. Analisando-se o desempenho dos concorrentes na indústria, é possível constatar ainda diferenças de desempenho entre as empresas nas situações de estratégias planejadas e estratégias emergentes. Embora exista a limitação inerente aos simuladores laboratoriais em termos de sua reprodução simplificada do ambiente empresarial real, o experimento contribuiu trazendo evidências dos efeitos da competição em oligopólios e também através da condução de uma abordagem metodológica original - o experimento controlado, para o enfoque deste problema tão presente nos mercados.

Palavras-chave: Planejamento Estratégico; Estratégias Deliberadas; Estratégias Emergentes; Jogos de Empresas; Competição.

\section{COMPARISON OF VALUE GENERATION STRATEGIES BETWEEN PLANNED AND EMERGING STRATEGIES: A STUDY BASED ON GAMES OF COMPANIES}

\section{ABSTRACT}

This study aims to analyze the economic results of the planned strategies compared to the emergent strategies in decision-making. The theoretical background emphasizes some aspects, like the strategy concept evolution throughout the time, the typology of strategies proposed by Mintzberg, the comparison between competition and cooperation, and the use of a business simulator as a tool for business research purposes. As a controlled experiment, the EGS simulator (Management Exercise Simulated) allowed comparison of the economic results of the two decision-making situations. The findings show that when planned strategies were implemented without corrections, the value generated (expressed by the internal rate of return IRR $=1.51 \%$ ) was greater than in the case of adjusted emerging strategies in three periods ( $I R R=1.40 \%)$. Comparing the two situations, it is possible to find a value added advantage of $7.86 \%$ in favor of the planned strategies, indicating the competition might be responsible for the value decreasing in real environment. Analyzing the performance degrees reached by the competitors, the ranking results show that there is no association between planned strategy and emerging strategies. Although the business simulators can be considered weak approximations for the business environment, the experiment contributed new evidence of the competition rise in oligopoly industries and a new methodological approach for studying this phenomenon.

Keywords: Strategic Planning; Intended Strategy; Emerging Strategies; Business Simulator; Competition. 


\section{COMPARACIÓN DE LA GENERACIÓN DE VALOR ENTRE ESTRATEGIAS} PLANIFICADASY LAS EMERGENTES: UN ESTUDIO BASADO EN JUEGOS DE EMPRESAS

\section{RESUMEN}

En el presente estudio se investigó los efectos económicos de las estrategias emergentes en comparación con las estrategias planificadasenla tomada de decisión y sus resultados diferenciales. Como referenciales teóricos se utilizaronlas escuelas de estrategias,las tipologíasde estrategias clasificadas por Mintzberg, un análisis acerca de la competición en mercados y el uso de los juegos de empresas como herramienta para la simulación de una realidad empresarial ycomo método de investigación. En el experimento controlado, los resultados del simulador EGS en las dos situaciones investigadas de toma de decisiones indicaron que las estrategias planificadas presentan mayor agregación de valor para la industria $(\mathrm{TIR}=1,51 \%)$, superior a las estrategias emergentes en tres períodos, en las cuales la agregación de valor ocurrió en menores niveles (TIR=1,40\%). Comparándoseambas situaciones, se percibe la diferencia de 7,9\% de valor a favorde la situación planificada,lo que sugiere que la competición establecida en la situación competitiva emergente haya sido responsable por la menor agregación de valor en esta industria. Cuando se analiza el desempeño de los competidores en la industria, es posible constatar lasdiferencias de desempeño entre las empresas en las situaciones de estrategias planificadas y estrategias emergentes. Aunque existala limitación inherente alossimuladores del laboratorio en cuanto a su reproducción simplificada del ambienteempresarial real, el experimento ayudó a traer pruebas de los efectos de la competencia en los oligopolios y también mediante la conducción de un enfoque metodológico original - experimento controlado, para abordar este problema tan presente en los mercados.

Palabras-claves: Planificación Estratégica; Estrategias Deliberadas; Estrategias Emergentes; Juegos de Empresas; Competición. 
Comparação da Geração de Valor entre as Estratégias Planejadas e as Estratégias Emergentes: Um Estudo Baseado em Jogos de Empresas

\section{INTRODUÇÃO}

O processo de tomada de decisões gerenciais possui elevado grau de subjetividade e uso de intuição, como resposta às mudanças impostas pelo ambiente econômico e ações concorrenciais. Mintzberg desenvolve este tema, confrontando o desvio das escolhas estratégicas efetivas, chamadas de estratégias emergentes, em relação às estratégias planejadas. Ainda como subsídio teórico, segundo Sauaia e Kallás (2004) as ações concorrenciais em um oligopólio objetivam inicialmente a conquista de rentabilidade adequada, tratadas como uma espécie de cooperação, até que se estabelece a competição em preços buscando maior participação de mercado, levando a perdas de rentabilidade. Como conclusão destes autores, a partir de um estudo em laboratório de gestão, as estratégias de cooperação geralmente se apresentam como estratégias de agregação de valor. Por outro lado, estratégias de competição se traduzem em aumentos de volumes, porém queda de preços. Partindo deste nivelamento teórico, desenvolve-se a abordagem comparativa dos resultados econômicos advindos das duas situações estratégicas- estratégias planejadas versus estratégias emergentes, estabelecendo-se a proposição teórica do estudo a ser verificada pelos dados empíricos, coletados em pesquisa experimental conduzida em sala de aula, com base nas técnicas de aprendizagem vivencial, e partindo-se do pressuposto de que a tomada de decisão com base na vigilância das ações e estilos dos concorrentes, caracterizada pelas estratégias emergentes, poderia gerar aumento de concorrência e com isto agregar menor valor para a indústria quando comparadas às estratégias planejadas.

\section{REVISÃO BIBLIOGRÁFICA}

\subsection{ESTRATÉGIA}

Segundo Mintzberg et alli (1998) o termo estratégia admite uma gama de definições: um plano, no qual a estratégia trata a maneira pela qual os líderes tentam estabelecer direções para as organizações, de foma a conduzí-las por determinado curso de ação; um truque, um processo para a obtenção de vantagem competitiva através do uso de estratagemas, riscos e táticas em um ambiente competitivo; um padrão, uma ação é determinada pelo comportamento; uma posição em que se define um posicionamento protegido a fim de buscar competitividade ou evitá-la; uma perspectiva que encerra a intenção e o comportamento em contexto coletivo. Os autores propõem que a visão 
clássica do planejamento estratégico, originalmente concebida em 1974 por Igor Ansoff está ultrapassada e inadequada para o contexto empresarial atual, extremamente dinâmico e competitivo, apresentando como argumentos as armadilhas e falácias encontradas no processo e a obsolescência intrínseca do planejamento estratégico inserido em um ambiente de contínua mudança. Seriam elas:

1. A falácia da pré-determinação (previsão para horizonte de tempo longo é impossível já que estratégia trata de ações em ambiente ilógico),

2. A falácia da separação (planejamento e execução como funções estanques)

3. A falácia da formalização (análise gerando síntese formal, o que se mostrou inadequado com o tempo).

Reunindo as três falácias, os autores definem a grande falácia: já que a análise não pode ser sintética, o planejamento estratégico nunca chegou a ser a realização de estratégia, e na verdade poderia ser chamado de programação estratégica, sendo usado apenas para formalizar, quando necessário, as conseqüências das estratégias já adotadas.

Assim, Mintzberg et alli (1994) redefiniram as novas funções a serem executadas pelos planejadores em termos da programação e execução da estratégia e formularam um modelo como “framework" para planejamento, concepção e execução de estratégias.

Zaccarelli (2000) também mostrou as modificações de concepção do planejamento estratégico no novo contexto competitivo, definindo a estratégia como processo de tomada de decisões em situação de incerteza e padrão ilógico. Baseando-se na concepção de Mintzberg, Zaccarelli (2000) defende que se deva redefinir totalmente o modelo de planejamento estratégico tradicional de Ansoff, devendo-se usar apenas a definição "estratégia" como ferramenta para dirigir as ações do estrategista na competição entre empresas no jogo competitivo, visando a obtenção de sucesso. Este sucesso deve ser entendido como dinâmico (algo sempre a perseguir) e não como fixo (estático). Assume como legados do modelo tradicional de planejamento o enriquecimento das análises através das análises SWOT, pela visão ambiental sistêmica propiciada, e como principal limitação o fato de desconsiderar que o ambiente competitivo possui caráter dinâmico e imprevisível, permeado por reações imprevistas dos competidores. Segundo ele, o maior problema das empresas não era de conotação interna, mas sim derivado da disputa com os concorrentes. Então redefine a estratégia como a busca do sucesso da empresa com base na criação de vantagens competitivas. Estas vantagens competitivas são os fins da existência da estratégia, a qual se constitui em meio para a obtenção destas vantagens, e seu valor em geral é bem maior do que o valor econômico que aparentam ter.

Revista Ibero-Americana de Estratégia - RIAE, São Paulo, v. 11, n. 1, p. 152-177, jan./abr. 2012. 
Comparação da Geração de Valor entre as Estratégias Planejadas e as Estratégias Emergentes: Um Estudo Baseado em Jogos de Empresas

Zaccarelli (2000) ainda classifica a estratégia como processo decisório, portanto com grau de incerteza e risco associados. Em outras palavras, a estratégia não segue o formalismo de problemas lógicos, para os quais há uma solução ótima. A estratégia também depende do estilo pessoal do estrategista. $\mathrm{O}$ autor desvenda conceitos de sucesso da estratégia e busca de vantagem competitiva como objetivo maior de qualquer negócio e apresenta novas classificações para situações de adoção de estratégias, ampliando as estratégias genéricas para um número maior de possibilidades, definindo tipos de estratégias complementares e classificando os possíveis tipos de vantagens competitivas.

Pelo fato de caracterizar-se como um problema de passagem, saindo de uma situação para outra buscando maior vantagem competitiva, deve-se buscar a identificação dos motivos de insatisfação com a situação atual da empresa para assim formular e implementar melhorias estratégicas.

\subsection{AS ESCOLAS DE PLANEJAMENTO ESTRATÉGICO}

Mintzberg et alli (1998) apresentam dez escolas de pensamento sobre a formulação de estratégia com perspectivas distintas e, juntamente, as qualificam quanto à visão que possuem do processo estratégico, conforme aperesentado no Quadro 1.

\begin{tabular}{|c|c|c|}
\hline ESCOLAS DE ESTRATÉGIA & $\begin{array}{c}\text { PROCESSO DE } \\
\text { ESTRATÉGIA }\end{array}$ & NATUREZA DAS ESCOLAS \\
\hline a) A Escola do Design & processo de concepção & Prescritiva \\
\hline b) A Escola do Planejamento & processo formal & Prescritiva \\
\hline c) A Escola do Posicionamento & processo analítico & Descritiva \\
\hline d) A Escola Empreendedora & processo visionário & Descritiva \\
\hline e) A Escola Cognitiva & processo mental & Descritiva \\
\hline f) A Escola de Aprendizado & processo emergente & Descritiva \\
\hline g) A Escola do Poder & processo de negociação & \\
\hline
\end{tabular}

Revista Ibero-Americana de Estratégia - RIAE, São Paulo, v. 11, n. 1, p. 152-177, jan./abr. 2012. 
Marcos Paixão Garcez \& Antonio Carlos Aidar Sauaia

\begin{tabular}{|l|c|c|}
\hline h) A Escola Cultural & processo de negociação & Descritiva \\
\hline i) A Escola Ambiental & processo coletivo & Descritiva \\
\hline j) A Escola de Configuração & processo de transformação & Contingencial \\
\hline
\end{tabular}

Quadro 1- Escolas de Estratégia e suas características.

Fonte: Mintzberg et alli, 1994.

Estas escolas podem ser agrupadas em três conjuntos. O primeiro conjunto, referente às três escolas iniciais, é de natureza prescritiva: a de design focaliza a formulação de estratégia como um processo de desenho informal, de concepção; a de planejamento focaliza o processo como separado e sistemático, e a escola de posicionamento focaliza a seleção de posições estratégicas no mercado. As outras seis escolas seguintes preocupam-se mais em descrever como as estratégias são formuladas (natureza descritiva). E um terceiro conjunto é representado somente pela escola de configuração, de natureza própria, contingencial. Maior detalhamento sobre as diferenças entre as escolas são obtidas no trabalho de Mintzberg et alli (1994) e revisitadas no estudo de Pereira e Toni (2002).

Tecem-se a seguir considerações sobre os aspectos de quatro fortes escolas, as escolas do design, do planejamento, do posicionamento e do aprendizado. A escola do Design foi a primeira a estudar estratégia, propondo a adequação das capacidades internas às possibilidades externas. Segundo Mintzberg et all (1998), seus principais teóricos foram Philip Selznick e Alfred K. Chandler. Nesta escola iniciou-se o uso do modelo SWOT, onde os pontos fortes e fracos internos da organização, chamado de ambiente interno, são tratados em contraponto às oportunidades e ameaças do ambiente externo. Após a determinação das estratégias, restaria então avaliar a melhor e implementá-la. Há clara separação entre o processo de concepção e a ação.

A escola do Planejamento assumiu muitas premissas da escola de design. Trata-se de um modelo, também baseado no modelo SWOT, com maior decomposição e especificação de cada uma de suas partes. O principal fator diferenciador em relação à escola do design relacionava-se à execução bastante formal da estratégia, com prescrição de etapas bem definidas. Segundo Mintzberg, o executivo principal constitui-se no arquiteto da estratégia, mas, na prática, sua função seria de aprová-las e não de elaborá-las, o que ficaria a cargo dos planejadores. Nesta época surgem duas importantes vertentes da estratégia, o planejamento de cenários e controle estratégico. Esta escola do Planejamento originou-se com a escola de Design, sendo o autor H. Igor Ansoff o mais influente desta corrente.

Revista Ibero-Americana de Estratégia - RIAE, São Paulo, v. 11, n. 1, p. 152-177, jan./abr. 2012. 
Comparação da Geração de Valor entre as Estratégias Planejadas e as Estratégias Emergentes: Um Estudo Baseado em Jogos de Empresas

A escola de Posicionamento teve como principal expoente Michael Porter com sua obra Competitive Strategy. Baseava-se em diversos conceitos das escolas do Design e do Planejamento, porém destaca-se maior ênfase na importância intrínseca das próprias estratégias influenciando o processo e à análise mais criteriosa das vantagens competitivas. Nesta escola as estratégias são genéricas, mas devem ser específicas para cada organização. Poucas estratégias-chaves são desejáveis, como por exemplo, a posição no mercado, e se este mercado é econômico e competitivo. Para analisar as alternativas, o estrategista adota modelos analíticos de forma a escolher as melhores posições. Após a análise e definição do posicionamento, as estratégias estão prontas para serem detalhadas e implementadas, sendo a estrutura de forças competitivas do mercado a determinante das estratégias de posicionamento deliberadas. Esta escola credita o risco da perpetuidade do negócio à indefinição do posicionamento genérico, chamadas de estratégias "meio-termo".

$\mathrm{Na}$ escola do aprendizado, o conceito principal é que os estrategistas aprendem ao longo do tempo. Quando as pessoas aprendem a lidar com determinada situação, e a organização está capacitada a respeito destas, as estratégias "emergem". Esta escola iniciou-se com Brian Quinn, com sua obra Strategies for change: logical incrementalism. Uma grande contribuição também foi dada por Karl Weick, cuja teoria abordou como a realidade emerge da interpretação e atualização, da reflexão e do exame, de experiências passadas e abordou ainda a importância de agir para aprender. Surgiram então três importantes focos de análise da aprendizagem organizacional: o aprendizado como criação do conhecimento, a abordagem de capacidades dinâmicas de Hamel e Prahalad e a teoria do caos (MINTZBERG et alli, 1994). Estas novas perspectivas de aprendizagem contribuem no sentido de representar um contrapeso à perspectiva racional que inicialmente dominou a teoria e a prática de administração estratégica. A aprendizagem referida aqui, baseada em experiências passadas, se dá ao longo do tempo e, na maior parte, coletivamente. Este aprendizado pode ocorrer em diversos setores, lugares múltiplos, e de diferentes maneiras, transformando estratégias emergentes em estratégias formalmente deliberadas. $\mathrm{O}$ papel da liderança passa a ser gerenciar o processo de aprendizado estratégico, focalizando padrões do passado que, mais tarde, podem vir a ser planos futuros e representar um guia para o comportamento geral.

Chaffee (1985) afirma que existem alguns aspectos em que os diversos autores e escolas demonstram convergência com relação à estratégia: (a) seu estudo diz respeito à organização e ao ambiente como inseparáveis; (b) a estratégia inclui tanto a ação tomada ou o conteúdo da estratégia quanto o processo pelo qual as ações são decididas e implementadas; (c) pode haver diferenças entre as estratégias planejadas, emergentes e realizadas; (d) existência tanto de estratégias em nível 
corporativo quanto em nível de negócios nas empresas; e finalmente, (e) a concepção da estratégia envolve tanto o exercício analítico como o conceitual.

\subsection{AS ESTRATÉGIAS DELIBERADAS E AS EMERGENTES}

Em termos de formulação de estratégias, Mintzberg (1998) classifica as estratégias em dois principais grupos: planejadas (pretendidas e deliberadas) e estratégias emergentes. Uma dada estratégia pode ser introduzida deliberadamente através de um processo de formulação (estratégia planejada ou pretendida) seguido de implementação (estratégia deliberada) ou emergir como uma resposta a uma situação nova (estratégia emergente).

Como subtipos, Mintzberg propõe a existência das estratégias pretendidas, deliberadas, não realizadas, emergentes e realizadas, conforme ilustrado na Figura 1. Segundo este autor, as estratégias pretendidas são planejadas para garantir a melhor forma de controle, mas não conseguem prever de forma acurada o futuro e mantém premissas adotadas para situações esperadas de forma a atingir os objetivos traçados.

Não é possível predeterminar nas empresas modelos precisos em suas atividades, e dessa forma, impô-los através de algum tipo de processo de planejamento formal, devido à existência de um ambiente complexo e imprevisível (MINTZBERG, 1998, p.317). Estratégias emergentes, por outro lado, derivam de ações tomadas pela empresa, mas não planejadas de forma explícita. Pelo fato das estratégias emergentes serem aparentemente flexíveis, elas estimulam o aprendizado sobrepujando o controle, já que as ações são tomadas à medida que as necessidades aparecem.

Figura 1 - Subtipos de Estratégias.

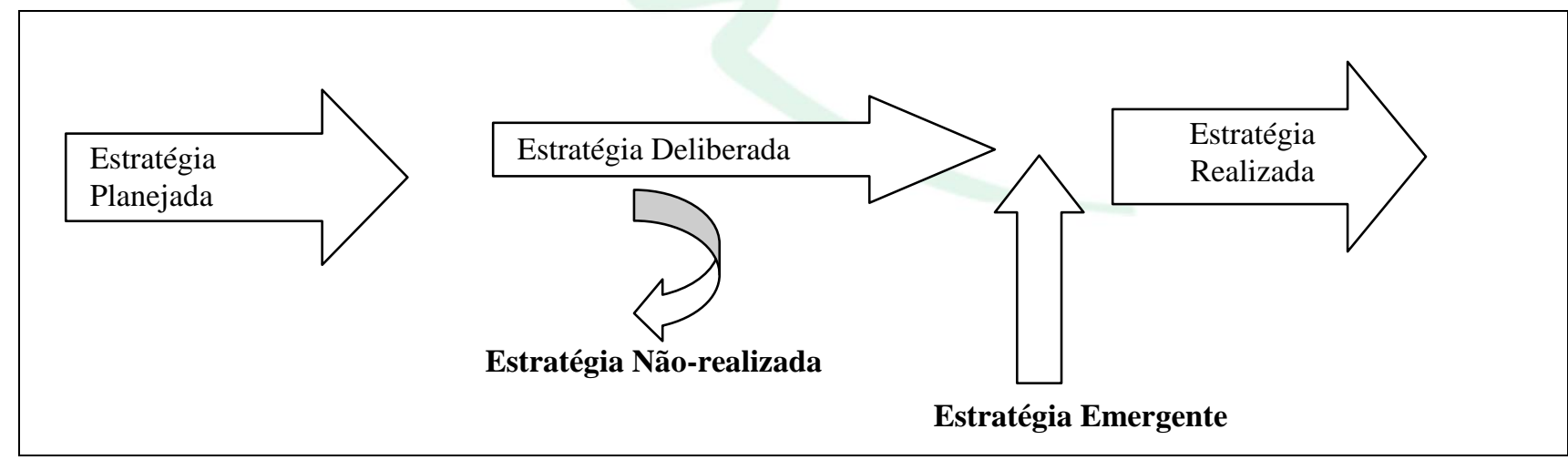

Fonte: Mintzberg et alli (1998, p. 19).

Chaffee (1985) também aborda a mesma questão anterior sob outra tipologia. De acordo com ele, existem três modelos de estratégias que envolvem os diversos conceitos: linear, adaptativo 
Comparação da Geração de Valor entre as Estratégias Planejadas e as Estratégias Emergentes: Um Estudo Baseado em Jogos de Empresas

e interpretativo. O modelo linear focaliza o planejamento e assume que a organização deve lidar com o ambiente; o modelo adaptativo foca mais os meios e assume que a organização deve mudar com o ambiente, e finalmente o modelo interpretativo foca mais os participantes e lida com o ambiente por meio de ações simbólicas e pela comunicação. Estes dois últimos modelos consideram que a organização e seus ambientes constituem um sistema aberto.

\subsection{MÉTODOS ATIVOS DE APRENDIZADO}

Consistem nas didáticas em que os principios de interação e cooperação entre os alunos reunidos em grupos podem ser desenvolvidos, através de técnicas cooperativas (ensino em pares, grupos de estudo e discussão). Também são considerados métodos de aprendizado ativo aqueles desenvolvidos em algumas técnicas individuais específicas, como os estudos de caso, ensino remoto (uso de computador) e estudo independente. Alguns estudos, explicitados no próximo tópico, demonstraram a alta potencialidade das técnicas de aprendizado ativo, nas quais o aluno é estimulado a agir e se posicionar sobre a matéria em pauta, reduzindo o automatismo e assim favorecendo o processo de aprendizado de forma mais efetiva, quando comparado aos métodos de ensino passivos, como, por exemplo, a aula expositiva. Ainda, maior eficácia é creditada aos métodos ativos de ensino em grupos comparados aos métodos ativos de ensino individuais.

\subsubsection{O ENSINO EM GRUPOS}

Segundo Godoy e Cunha (1997), o ensino em pequenos grupos teve origem no início do século, através do movimento Escola Nova que questionava o ensino autoritário da época; assim, a técnica de trabalhos em grupos pertence aos chamados métodos ativos que se caracterizam pela utilização do grupo como meio de formação pedagógica, uso de motivações intrínsecas (e não extrínsecas como nos métodos passivos tradicionais de ensino, como a aula expositiva) e o desenvolvimento da iniciativa dos alunos para o que deva ser aprendido. O aluno passa a exercer papel principal e em sua atividade se concentram tanto os professores como os alunos. O ensinar subordina-se ao aprender.

Os mesmos autores defendem que, trabalhando em grupos, os alunos aprendem mais, utilizam mais o raciocínio lógico, sentem-se mais satisfeiitos e toleram mais as diferenças. Este tipo de ensino presta-se muito bem à finalidade educativa e formativa, relegando ao segundo plano a finalidade informativa ou instrutiva. Se bem conduzido, apresenta como resultado a aprendizagem individualizada, porém atingida por meio de discussões em pequenos grupos. Entre seus objetivos 
está o desenvolvimento da comunicação, competências intelectuais e profissionais e crescimento pessoal.

Diversos outros autores desenvolveram estudos sobre as características do ensino em grupos, com alto nível de detalhamento e dedicando aprofundadas análises às questões do diálogo, interação aluno-aluno e interação aluno-professor, como se vê em Cooper (1996) e Weimer (1990). Ainda há autores que especificam detalhadamente diferentes técnicas de desenvolvimento com distintos agrupamentos, como os trabalhos passo a passo (step-by-step), trabalhos em pares, trabalho em projetos (como o caso deste estudo), como apresentado por Jaques (1992). Seus principais objetivos são: desenvolvimento da comunicação, competências intelectuais e profissionais e crescimento pessoal - tanto dos alunos como do professor.

As estratégias para maximização dos resultados referem-se ao arranjo dos assentos para facilitar interação, expectativas e regras gerais bem definidas, segurança (o aluno não deve se sentir inseguro em contribuir) e permitir a discussão dividindo em grupos pequenos de 2 a 3 alunos, sem a participação do professor nesta discussão preliminar. As habilidades requeridas do professor em ensinos em pequenos grupos referem-se ao saber explicar, questionar, ouvir, responder, sintetizar e dar fechamento. Dentre as principais técnicas para ensino em pequenos grupos, temos o seminário, o método do caso e os jogos de empresas, considerado este último como pertencente à linha pedagógica do ensino experimental.

\subsubsection{O APRENDIZADO VIVENCIAL}

Na obra de Halpern (1994), voltado ao estudo dos métodos de aprendizado ativo, é possível encontrar capítulos dedicados ao desenvolvimento da criatividade nos alunos, ao aprendizado cooperativo em sala de aula e ao comparativo entre as diversas técnicas de aprendizado ativo. Dentre as mais recentes técnicas surgiu a revisitação do aprendizado vivencial, abordado vastamente em Kolb (1984), para quem as pessoas aprendem a partir de sua vivência. Antes, o aprendizado vivencial era abordado apenas nos estudos de educação infantil. Kolb também traz importantes contribuições quanto às distinções de diferentes ofícios em termos de necessidades de capacidades reflexivas versus objetivas e natureza do pensamento abstrato versus concreto, sob a luz das teorias do aprendizado experimental de Piaget, Dewey e Lewin.

Discorrendo sobre o aprendizado vivencial, Kolb (1984) alega que este se dá através de transações do indivíduo com o ambiente, explicitando as tentativas recentes de caracterização do pensamento como não linear, enquanto tradicionalmente se defendia tratar-se de multilinear. Este autor propõe um novo modelo em termos das complexidades comportamentais, simbólicas, afetivas

Revista Ibero-Americana de Estratégia - RIAE, São Paulo, v. 11, n. 1, p. 152-177, jan./abr. 2012. 
Comparação da Geração de Valor entre as Estratégias Planejadas e as Estratégias Emergentes: Um Estudo Baseado em Jogos de Empresas

e perceptivas, sendo que o aprendizado experimental passa pelas fases de aquisição, especialização e integração. Sobre o executivo, Kolb (1984) comenta que o desenvolvimento de grandes habilidades intuitivas e comportamentais, como declaradas por Mintzberg, se assemelha em estrutura ao aprendizado por tentativa e erro em crianças.

Assim, para simplificar e adequar ao contexto gerencial se pode considerar por aprendizado experimental ou por experiência, aquele em que as vivências passadas e presentes redirecionam o processo de tomada de decisões futuras. No contexto do ensino gerencial, este processo se dá através da experimentação dos alunos no contato de vivência diária com a realidade do empresário, como também através das modificações constantes nas condições de formulação do plano de negócios, provocando o processo de tentativa e erro. Este ensino deveria então buscar a integração de diferentes vertentes, evitando a compartimentalização do aprendizado e trazendo a possibilidade de conexão com outras áreas do conhecimento e rellexão. A reforma dos currículos em escolas gerenciais tem sido utilizada para atenuar este problema e estimular o aprendizado reflexivo (ROGLIO, 2006, p.8; MONTEIRO, M.F., 2000). Parte-se da premissa de que o ensino deve ser integrativo e pode ser organizado em três tipos: (i) atividades centradas em objetivos principais; (ii) ênfase no conteúdo (integração horizontal e integração vertical - através de associações e discriminações); e (iii) ênfase em módulos centrados na solução de problemas (SANT'ANNA, 1979). A integração deve ser obtida pelo aluno, cabendo ao professor o papel de facilitador do processo-aprendizagem, devendo estimular o uso do conhecimento passado e orientar a obtenção do novo conhecimento (SANT'ANNA, 1979; MONTEIRO, M. F., 2000).

\subsection{OS JOGOS DE EMPRESAS COMO MÉTODO ATIVO VIVENCIAL}

Segundo Sauaia (1997), no jogo de empresas os alunos exercitam análise de problemas empresariais e tomam decisões em organizações simuladas descritas em relatórios operacionais e financeiros, o que possibilita o exercício de estratégias, sem os riscos de desempenho de uma empresa real. Os jogos de empresas se fundamentam em um modelo de simulação no qual as características de uma determinada empresa e indústria e do ambiente externo são apresentadas de forma aproximada às situações reais para que decisões sejam tomadas. Específicamente, a partir da descrição detalhada da situação financeira, patrimonial, estratégica, organizacional e histórica de uma empresa fictícia, os participantes do jogo tomam decisões em rodadas sucessivas e acompanham os resultados destas decisões. Desta forma, a situação problema está em constante mutação, reproduzindo o caráter dinâmico do ambiente de negócios.

Revista Ibero-Americana de Estratégia - RIAE, São Paulo, v. 11, n. 1, p. 152-177, jan./abr. 2012. 
O jogo de empresas consiste das etapas de preparação, instruções, ensaio, condução do jogo, análise do jogo terminado, busca de generalizações para os resultados, fechamento e complementação. Pressupõe a preparação mínima do aluno e de estar disposto a enfrentar situações não estruturadas, não determinísticas e probabilísticas. A evolução da tecnologia da informação permitiu a construção de jogos mais complexos e o rápido processamento dos dados entre as rodadas de tomada de decisão, auxiliando sua difusão no ambiente de ensino. As simulações empresariais são bastante utilizadas atualmente em cursos de graduação, MBA e treinamento gerencial. Segundo Tanabe (1977), um Jogo de Empresas diferencia-se de Simulação e Teoria dos Jogos.

\section{METODOLOGIA DE PESQUISA, COLETA E PROCESSAMENTO DOS DADOS}

A pesquisa pode ser classificada como um experimento controlado, utilizando uma das técnicas de aprendizado ativo, o laboratório de jogos de empresas como método ativo de aprendizado experimental, em ambiente empresarial simulado. O jogo simula a realidade do ambiente de negócios de forma aproximada, naturalmente com menor complexidade. Assim, a metodologia fez uso do ambiente controlado do laboratório de simulação de uma disciplina de Jogos de empresas.

A pesquisa experimental é entendida como levantamento de dados com finalidades “explicativas, avaliativas e interpretativas, tendo como objetivos a aplicação, a modificação e ou a mudança de alguma situação ou fenômeno.” (LAKATOS; MARCONI, 1988, p.19). De acordo com Martins (1992), a investigação experimental adota o critério de manipulação de uma ou mais variáveis independentes, sob adequado controle, a fim de se observar e interpretar as modificações e reações ocorridas na variável dependente. O estudo experimental baseia-se em um plano de investigação, de forma que sejam obtidas respostas para as perguntas da pesquisa, seguido da coleta dos dados e análise.

Deve-se, no entanto, salientar que o estudo desta natureza em ciências sociais aplicadas, como é o caso da Administração, não pode ser comparado aos estudos de ciências naturais, que fazem uso do experimento como uma das estratégia preferencial de pesquisa. Como não é possível estabelecer controle total sobre o experimento, classifica-se então o jogo de empresas de forma mais adequada como um experimento semi-controlado.

Adota-se como simulador a ferramenta EGS - Exercício de Gestão Simulada, como descrito em Sauaia (2006). O simulador EGS possui um conjunto de algoritmos matemáticos que 
Comparação da Geração de Valor entre as Estratégias Planejadas e as Estratégias Emergentes: Um Estudo Baseado em Jogos de Empresas

representam de maneira simplificada aspectos da macroeconomia, da microeconomia e da realidade competitiva. Para um dado conjunto de entradas (decisões) das diversas empresas, os algoritmos geram um determinado conjunto de saídas (resultados) em cada período de operação trimestral.

Nesta pesquisa, o simulador EGS simulou o caso de uma indústria caracterizada pela oferta de um produto eletroeletrônico comercializado somente no mercado doméstico. Os 12 estudantes de mestrado e doutorado que participaram desta vivência, após a familiarização com o modelo econômico do simulador, com o jogo e tendo uma sensibilidade inicial da ferramenta propiciada em 4 rodadas de tomada individual de decisões, foram reunidos em 6 duplas, cada qual se constituindo em uma das seis empresas de uma indústria em particular. As empresas devem tomar decisões mercadológicas, operacionais e financeiras, todas submetidas às mesmas condições iniciais e ao mesmo ambiente macroeconômico.

Tomam-se decisões referentes a políticas de preço (variável de curto prazo), investimentos em melhoria dos produtos (gastos em pesquisa e desenvolvimento com resultados de médio prazo) e investimentos em serviços de comercialização (gastos em marketing - propaganda e promoção, ponto de venda e vendedores: curto e médio prazo). A fábrica opera em um turno normal de até 8 horas ou com jornada extra de até 4 horas adicionais com custo de operação $50 \%$ maior. Pode produzir no limite máximo até $150 \%$ da capacidade instalada e necessita de insumo (matéria prima), equipamentos de produção e mão de obra. Todas as empresas iniciam com saldo de caixa positivo.

Para atender a demanda gerada, a oferta foi formada pela produção do período somada ao estoque de produtos acabados de períodos anteriores. As condições de demanda eram afetadas e sinalizadas por três índices econômicos: de preços (IGP), de sazonalidade (IVE) e de atividade econômica (IAE). Estes índices podem variar alterando-se radicalmente o cenário econômico. No simulador, a indústria podia operar com um número de firmas que variava de um (monopólio) a nove fabricantes (oligopólio, concorrência monopolística ou concorrência perfeita). O EGS constitui-se em simulador interativo em que todas as empresas partiram de situação inicial idêntica, o que facilitou a avaliação de desempenho verificado pelo indicador econômico TIR - taxa interna de retorno. Os resultados dependiam do ambiente econômico (retratado pelos indicadores IGP, IVE e IAE) que afetou o equilíbrio de mercado, e das relações de oferta e demanda a partir das estratégias adotadas pelas empresas concorrentes.

Apresenta-se de forma ilustrativa na figura 2 o modelo conceitual de análise empregado, sendo que a análise setorial se refere ao desempenho da indústria em sua totalidade e a análise empresarial compara o desempenho entre as empresas.

Revista Ibero-Americana de Estratégia - RIAE, São Paulo, v. 11, n. 1, p. 152-177, jan./abr. 2012. 
Figura 2- Modelo conceitual desta pesquisa.

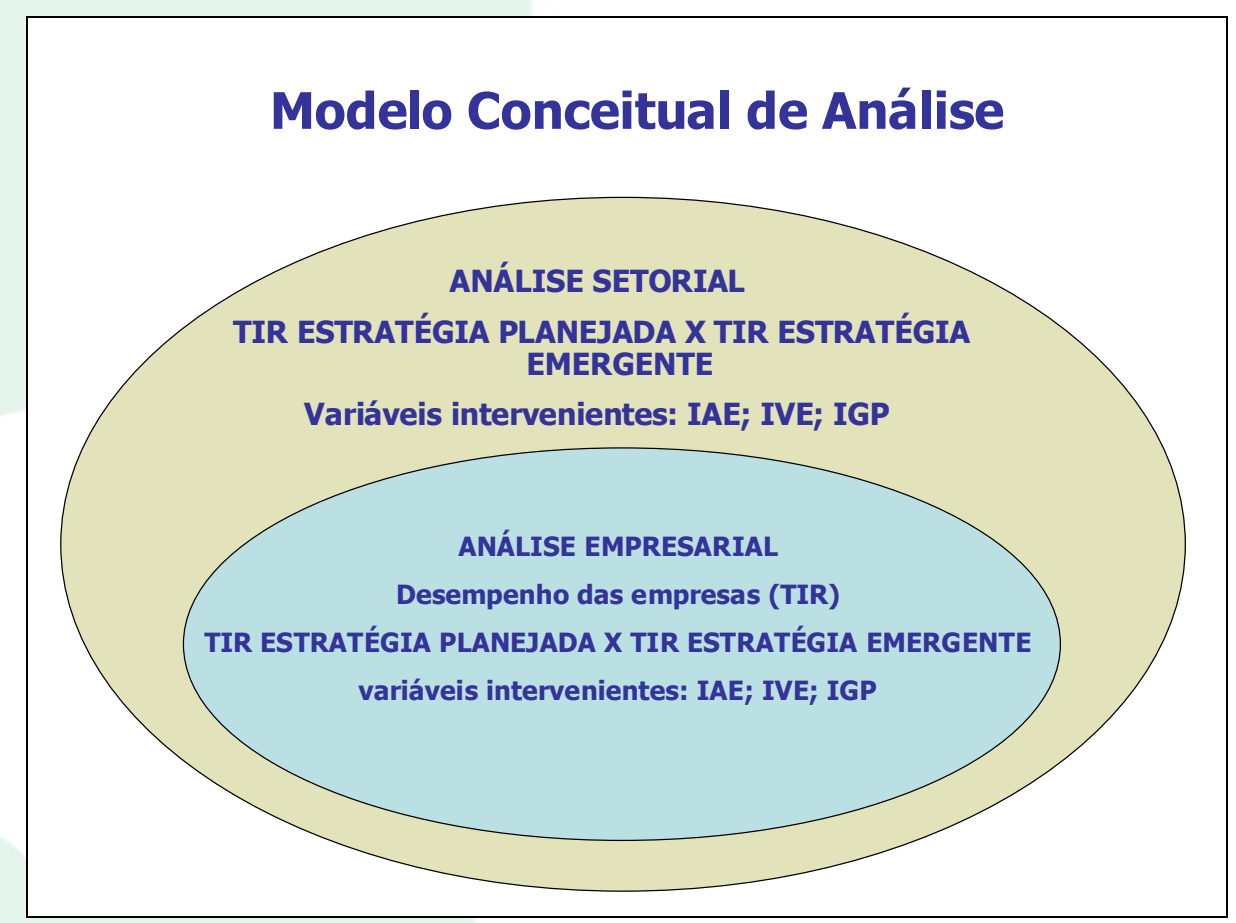

Fonte: Elaborado pelos autores.

Como padrão de referência das estratégias planejadas, ou seja, a tomada de decisões sem informações dos concorrentes utilizou-se o planejamento operacional de três períodos, com o que se calculou a taxa interna de retorno (TIR) de cada empresa e conjunta da indústria. Compararam-se então com os resultados consolidados das estratégias emergentes, derivadas das decisões intermitentes em três períodos, com o que também se tem a taxa interna de retorno (TIR) individual por empresa e conjunta da indústria. Para o cálculo da TIR, adota-se a seguinte fórmula (SAUAIA, 2010, p.39):

$\mathrm{PLE}_{0}=\left[\mathrm{D}_{1} /(1+\mathrm{TIR})\right]+\left[\mathrm{D}_{2} /(1+\mathrm{TIR})^{2}\right]+\left[\left(\mathrm{D}_{3} /(1+\mathrm{TIR})^{3}+\mathrm{PLE}_{3}\right]\right.$

Sendo: PLEn = Patrimônio Líquido no período $\mathrm{n} ; \mathrm{Dn}=$ Dividendos pagos no período $\mathrm{n}$

Para o cálculo da TIR na indústria, utiliza-se estatística descritiva univariada simples, com o cálculo das médias aritméticas das taxas internas de retorno individuais das empresas.

Revista Ibero-Americana de Estratégia - RIAE, São Paulo, v. 11, n. 1, p. 152-177, jan./abr. 2012. 
Comparação da Geração de Valor entre as Estratégias Planejadas e as Estratégias Emergentes: Um Estudo Baseado em Jogos de Empresas

\section{PROBLEMA DE PESQUISA E OBJETIVOS}

O processo de tomada de decisões possui como componentes, além do conhecimento advindo do correto uso de informações disponíveis, uma alta dose de intuição e subjetividade. $\mathrm{Na}$ pesquisa de Sauaia e Kallás (2004), as ações concorrenciais em um oligopólio visam em um primeiro momento a conquista de rentabilidade adequada, tratada com uma espécie de cooperação, até que se estabelece a competição em preços buscando maior participação de mercado, levando a perdas de rentabilidade. Segundo os autores, no laboratório de gestão, em geral as estratégias de cooperação se traduzem em estratégias de agregação de valor. Por outro lado, estratégias de competição se explicitam em aumentos de volumes e queda de preços.

Partindo deste nivelamento teórico, estabeleceu-se a proposição teórica a ser verificada pelos dados empíricos, partindo-se do pressuposto de que a tomada de decisão com base na vigilância das ações e estilos dos concorrentes, caracterizada pelas estratégias emergentes, poderia gerar aumento de concorrência e com isto agregar menor valor para a indústria quando comparada às estratégias planejadas. Formula-se assim a proposição teórica do estudo, a seguir descrita:

Proposição teórica: As decisões dos fabricantes baseadas em estratégias emergentes adicionam menor valor na indústria como um todo, quando comparadas às decisões baseadas em estratégias planejadas.

A proposição que as estratégias emergentes adicionam menor valor que às estratégias planejadas, carregam implícitamente dois direcionadores do fenômeno:

a. Tendência de "busca de agregação de valor nas estratégias planejadas", que embora também possam conter aspectos de competição visam em primeira instância a maximização do valor.

b. Acirramento de competição com as estratégias emergentes, como tentativas de recuperação de volumes, share e/ou manutenção de valor, à medida que perdas e ganhos se evidenciam nas ações consecutivas.

Revista Ibero-Americana de Estratégia - RIAE, São Paulo, v. 11, n. 1, p. 152-177, jan./abr. 2012. 


\section{ANÁLISE DOS RESULTADOS}

Apresentam-se e discutem-se a seguir os resultados segundo dois agrupamentos de análise: a camada de análise setorial (desempenho da indústria) e a camada de análise das empresas (comportamento estratégico).

\subsection{CAMADAS DE ANÁLISE SETORIAL - DESEMPENHO DA INDÚSTRIA}

$\mathrm{Na}$ figura 3 apresentam-se os resultados da indústria tanto nas estratégias planejadas como nas estratégias emergentes. Destaca-se que no primeiro período (trimestre 1), os resultados são idênticos, já que a estratégia realizada coincidia com a planejada, já que não se conhecia até aquele momento a ação dos concorrentes na indústria. Nos períodos subsequentes, é possível perceber claramente o melhor resultado obtido com as estratégias planejadas, que geraram taxa interna de retorno média acumulada para a indústria de 1,51\%, contra 1,40\% para as estratégias emergentes, o que resulta em diferença de $7,9 \%$ entre as duas situações.

Figura 3 - Taxa interna de retorno das estratégias trimestrais.

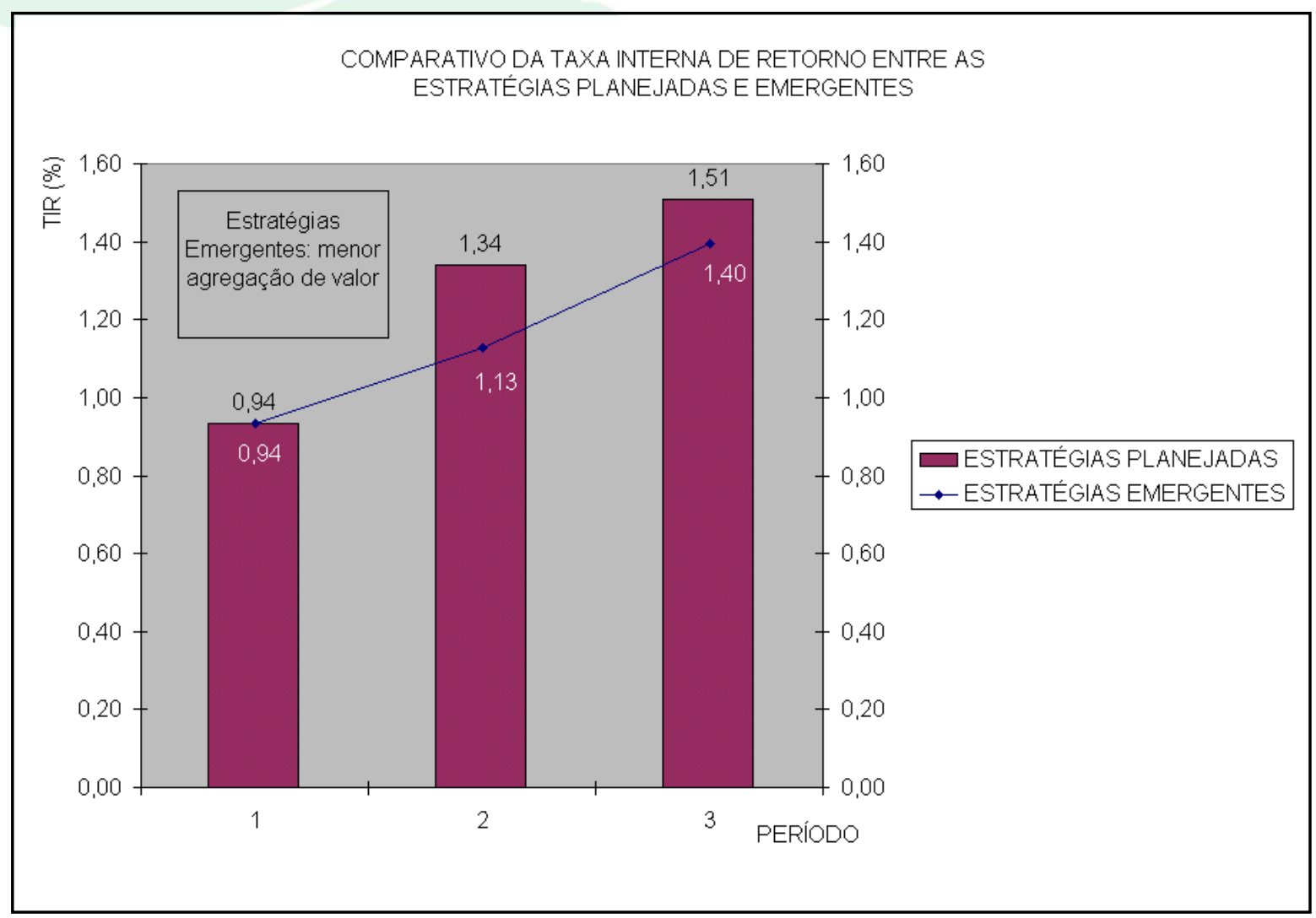

Fonte: Elaborado pelos autores.

Revista Ibero-Americana de Estratégia - RIAE, São Paulo, v. 11, n. 1, p. 152-177, jan./abr. 2012. 
Comparação da Geração de Valor entre as Estratégias Planejadas e as Estratégias Emergentes: Um Estudo Baseado em Jogos de Empresas

Assim, evidencia-se a menor agregação de valor na situação de estratégias emergentes, denotando uma concorrência prejudicial ao resultado da indústria.

\subsection{ANÁLISE DO COMPORTAMENTO ESTRATÉGICO DAS EMPRESAS}

Apresenta-se na Tabela 1 a variação dos índices econômicos nos períodos em relação aos períodos imediatamente anteriores. Em todo o horizonte de tempo, o IGP cresceu 1,2\%; o IAE cresceu $10 \%$. O IVE apresentou variações positivas e negativas.

Tabela 1- Variação dos índices econômicos nos períodos.

\begin{tabular}{|c|c|c|c|c|}
\hline \multirow{2}{*}{ ÍNDICE } & \multicolumn{4}{|c|}{ PERÍODO } \\
\cline { 2 - 5 } & INICIAL & TRIMESTRE 1 & TRIMESTRE 2 & TRIMESTRE 3 \\
\hline IGP/Variação & 100 & $100,2 / 0,20 \%$ & $100,7 / 0,50 \%$ & $101,2 / 0,50 \%$ \\
\hline IVE/Variação & 100 & $95,0 /-5 \%$ & $115,0 / 21,05 \%$ & $90 /-21,74 \%$ \\
\hline IAE/Variação & 100 & $101,0 / 1 \%$ & $103,0 / 1,98 \%$ & $110 / 6,80 \%$ \\
\hline
\end{tabular}

Fonte: Elaborado pelos autores.

Nas Tabelas 2, 3 e 4, e nas Figuras 4 e 5, apresentam-se os resultados empíricos para o desempenho das empresas nas estratégias planejadas e emergentes. No que se refere às estratégias planejadas, não só os melhores desempenhos absolutos em termos de rentabilidade foram alcançados pelas empresas $6(2,36 \%)$ e 1 (2,13\%), como também elas apresentaram maior consistência do crescimento desta rentabilidade (assertividade), medido pelos altos valores dos coeficientes de determinação r2 (0,8862 e 0,8692 respectivamente). Interessante destacar a baixa assertividade do crescimento da empresa 2 nas estratégias planejadas $(0,1189)$.

Revista Ibero-Americana de Estratégia - RIAE, São Paulo, v. 11, n. 1, p. 152-177, jan./abr. 2012. 
Marcos Paixão Garcez \& Antonio Carlos Aidar Sauaia

Tabela 2 - Taxa interna de retorno trimestral das empresas nas estratégias deliberadas iniciais (decisões declaradas no Plano de Gestão, simuladas sem revisão).

\begin{tabular}{|c|c|c|c|c|c|}
\hline \multicolumn{5}{|c|}{ TAXA INTERNA DE RETORNO - ESTRATÉGIAS PLANEJADAS } & \multirow{2}{*}{$\mathrm{r}^{2}$} \\
\hline EMPRESA & NOME & TRIMESTRE 1 & TRIMESTRE 2 & TRIMESTRE 3 & \\
\hline 1 & HI S/A & 0,85 & 1,92 & 2,13 & 0,8692 \\
\hline 2 & VAMO Q. VAMO S/A & 1,74 & 2,34 & 1,95 & 0,1189 \\
\hline 3 & ROA S/A & 0,79 & 2,03 & 2 & 0,7314 \\
\hline 4 & SINTOTEC S/A & 1,23 & $-1,54$ & $-0,13$ & 0,241 \\
\hline 5 & SET SOLUTION S/A & $-0,2$ & 1,16 & 0,75 & 0,4636 \\
\hline 6 & D\&M S/A & 1,2 & 2,14 & 2,36 & 0,8862 \\
\hline \multicolumn{2}{|c|}{ Média aritmética da TIR na indústria } & 0,94 & 1,34 & $\mathbf{1 , 5 1}$ & \\
\hline
\end{tabular}

Fonte: Elaborado pelos autores.

Tabela 3 - Taxa interna de retorno por período para as empresas através das estratégias emergentes (decisões intermitentes no laboratório).

\begin{tabular}{|c|c|c|c|c|c|}
\hline \multicolumn{5}{|c|}{ TAXA INTERNA DE RETORNO - ESTRATÉGIAS EMERGENTES } & \multirow{2}{*}{$r^{2}$} \\
\hline EMPRESA & NOME & TRIMESTRE 1 & TRIMESTRE 2 & TRIMESTRE 3 & \\
\hline 1 & HI S/A & 0,85 & 1,35 & 1,98 & 0,9956 \\
\hline 2 & VAMO Q. VAMO S/A & 1,74 & 2,15 & 2,31 & 0,9397 \\
\hline 3 & ROA S/A & 0,79 & 1,55 & 1,64 & 0,8284 \\
\hline 4 & SINTOTEC S/A & 1,23 & $-1,17$ & 0,27 & 0,1579 \\
\hline 5 & SET SOLUTION S/A & $-0,2$ & 0,91 & 0,40 & 0,2915 \\
\hline
\end{tabular}

Revista Ibero-Americana de Estratégia - RIAE, São Paulo, v. 11, n. 1, p. 152-177, jan./abr. 2012. 
Comparação da Geração de Valor entre as Estratégias Planejadas e as Estratégias Emergentes: Um Estudo Baseado em Jogos de Empresas

\begin{tabular}{|c|c|c|c|c|c|}
\hline \multirow{6}{*}{ D\&M S/A } & 1,2 & 1,98 & 1,78 & 0,5124 \\
\hline Média aritmética da TIR na indústria & 0,94 & 1,13 & $1,13 \quad \mathbf{1 , 4 0}$ \\
\hline
\end{tabular}

Fonte: Elaborado pelos autores.

Tabela 4 - Ranking de desempenho das empresas.

\begin{tabular}{|c|c|c|c|}
\hline \multicolumn{5}{|c|}{ RANKING DE DESEMPENHO DAS EMPRESAS } \\
\hline \multirow{2}{*}{ EMPRESA } & & $\begin{array}{c}\text { ESTRATÉGIAS } \\
\text { PLANEJADAS }\end{array}$ & $\begin{array}{c}\text { ESTRATÉGIAS } \\
\text { EMERGENTES }\end{array}$ \\
\hline $\mathbf{1}$ & HI S/A & 2 & 2 \\
\hline $\mathbf{2}$ & VAMO Q. VAMO S/A & 4 & 4 \\
\hline $\mathbf{3}$ & ROA S/A & 3 & 6 \\
\hline $\mathbf{4}$ & SINTOTEC S/A & 6 & 5 \\
\hline $\mathbf{5}$ & SET SOLUTION S/A & 5 & 3 \\
\hline
\end{tabular}

Fonte: Elaborado pelos autores.

O ranking de resultados das empresas diferiu substancialmente nas situações estratégias planejadas e estratégias realizadas, como pode ser percebido na tabela 4. Ilustrativamente, o desempenho comparativo pode ser verificado nas figuras 4 e 5 .

Revista Ibero-Americana de Estratégia - RIAE, São Paulo, v. 11, n. 1, p. 152-177, jan./abr. 2012. 
Figura 4 - TIR das Empresas nas Estratégias Planejadas.

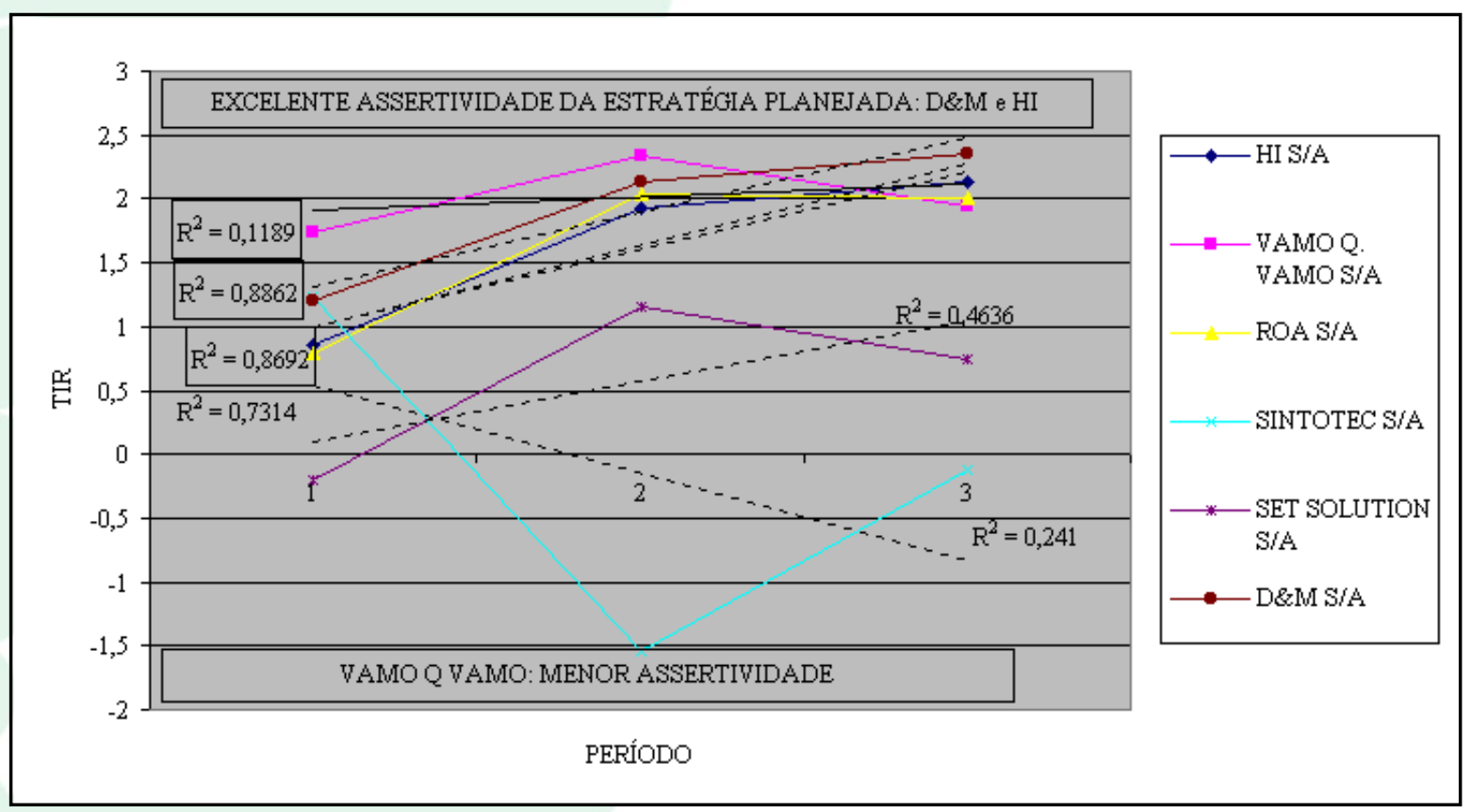

Fonte: Elaborado pelos autores.

Figura 5 - TIR das Empresas nas Estratégias Emergentes.

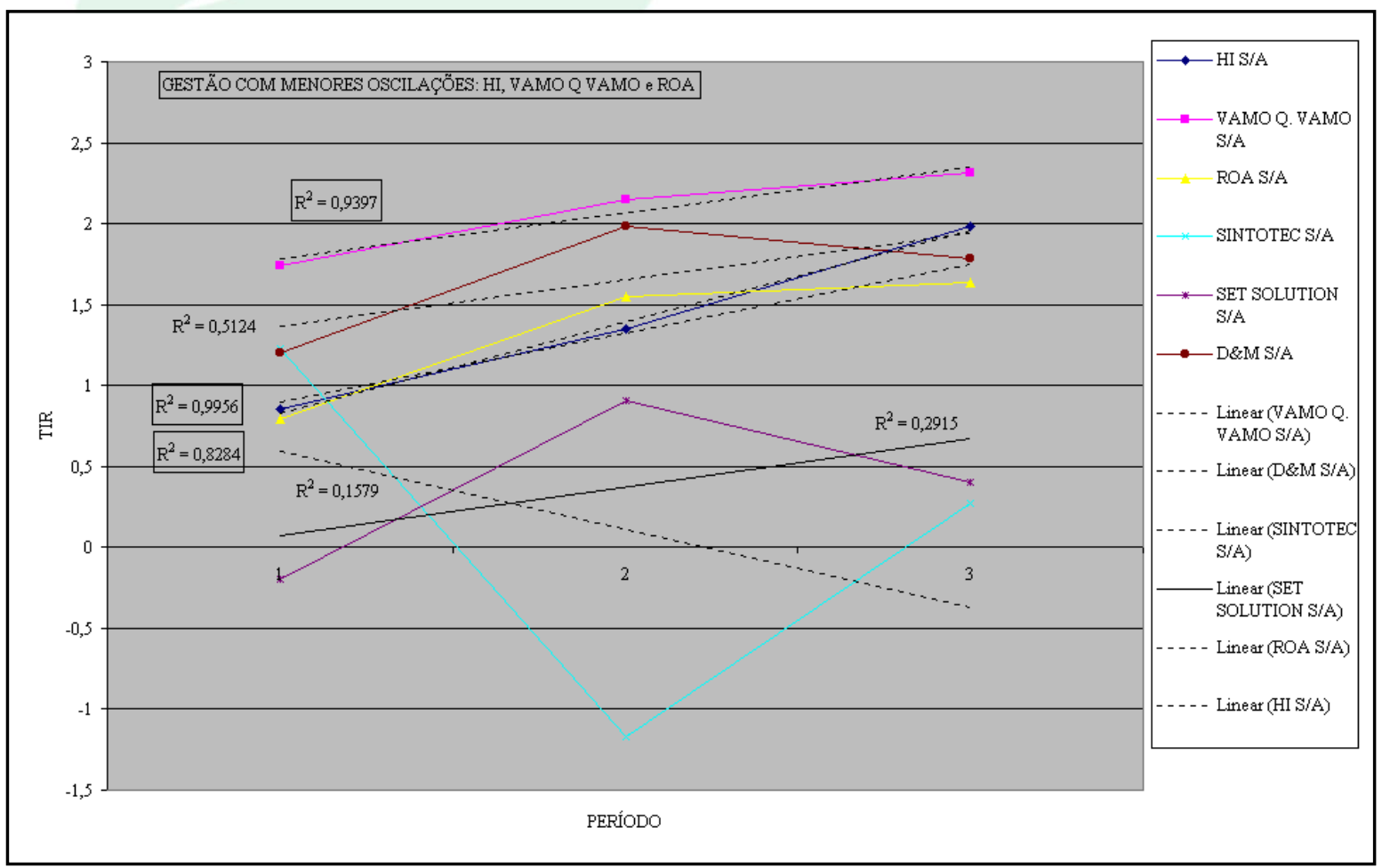

Fonte: Elaborado pelos autores.

Revista Ibero-Americana de Estratégia - RIAE, São Paulo, v. 11, n. 1, p. 152-177, jan./abr. 2012. 
Comparação da Geração de Valor entre as Estratégias Planejadas e as Estratégias Emergentes: Um Estudo Baseado em Jogos de Empresas

Os melhores resultados nas estratégias emergentes foram apresentados pelas empresas 2 $(2,31 \%)$ e $1(1,98 \%)$. Nesta situação, no entanto, os melhores ajustes do crescimento, expressos pelos coeficientes de determinação, foram apresentados pelas empresas $1(0,9956), 2(0,9397)$ e 3 $(0,8284)$. A empresa 2, que havia apresentado apenas o quarto desempenho na situação planejada e baixa assertividade, passou a ocupar a posição de melhor rentabilidade e aumentou de forma muito significativa sua assertividade $(0,9397)$ nas estratégias emergentes, o que denota sua capacidade de aprendizagem e tomada de decisões em situação real.

\section{DISCUSSÃO DOS RESULTADOS E CONCLUSÕES}

A partir dos resultados observados, a proposição teórica do estudo é validada. Assim, existe a possibilidade de que a competição em um oligopólio destrua valor na indústria, ou reduza seu potencial de agregação de valor (como evidenciado pelos dados empíricos deste estudo). Os resultados corroboram os achados do estudo de Sauaia e Kallás (2004), no qual foi evidenciada a prevalência da competição sobre a cooperação em um ambiente simulado de jogos de empresas em situação de oligopólio, como neste estudo. Dada a tendência de competição que levou à redução ou destruição de valor, observam-se na realidade empresarial oligopolista, como medidas de proteção de margens, o início da formação de cartéis, blocos ou associações industriais, decorrendo disto a necessidade de fiscalização e regulação de orgãos governamentais de forma a garantir a proteção ao consumidor e a manutenção do livre mercado e da concorrência leal. Também foi possível concluir que não existe associação entre desempenho nas estratégias planejadas e reais, ou seja, nem sempre a melhor estratégia planejada se confirma como a melhor na realidade.

Constatou-se ainda que as estratégias planejadas dos grupos ocuparam-se da geração de valor, distribuídas em intervalos que se situavam desde as estratégias de diferenciação por aumento das margens de contribuição em alguns grupos, até estratégias de liderança em custo e ganho de volume, por aumento da eficiência operacional e ganho de escala em outros. Nas situações de estratégias emergentes, em função dos resultados colhidos no período anterior, os grupos procuraram realizar ajustes corretivos, de forma a melhorarem sua posição competitiva relativa aos concorrentes e intensificando a competição, o que pode denunciar comportamento errático referente às estratégias planejadas, consubstanciados pelas tentativas de recuperação de participações de mercado e redução das margens e, por conseguinte, depressão dos resultados financeiros potenciais.

Embora os resultados possam à primeira vista parecer contra-intuitivos segundo o que preconiza a escola do aprendizado de Mintzberg et alli (1994) - para a qual as estratégias 
emergentes provêem a flexibilidade de ajustes não propiciada pelas estratégias planejadas, há que se analisar as condições de contorno do experimento, que evoluiu de uma concorrência perfeita para uma concorrência monopolista, além da oscilação relativa dos indicadores macroeconômicos e existência de custos de transação, como por exemplo, grande desbalanceamento entre a oferta e a procura, e ainda a escassez momentânea de oferta de matéria-prima que elevou sobremaneira os custos de aquisição deste fator de produção.

Como nova proposição, embora não evidenciado nos dados empíricos deste estudo em vista do pequeno horizonte de rodadas sucessivas, pode-se inferir que na situação de oligopólio, e com o passar do tempo, a competição se acirra em níveis crescentes, até que começa a surgir certa tendência de cooperação que minimiza as perdas, podendo acarretar em mudança do comportamento e reversão da vantagem para as estratégias emergentes, quando comparadas às planejadas em horizonte de tempo mais longo.

\subsection{CONSIDERAÇÕES FINAIS}

Como contribuição, o estudo corrobora alguns resultados de estudos anteriores sobre cooperação versus competição em oligopólios, além de trazer uma abordagem metodológica de análise original no que tange à comparação das estratégias planejadas e emergentes em um experimento controlado de simulação laboratorial.

As limitações inerentes a este tipo de experimento devem ser destacadas, como a simplificação da realidade imposta pelo número limitado de variáveis presentes no simulador, os cuidados quanto à generalização, em decorrência do pequeno número de períodos de simulação empreendidos e a pequena base de dados primários.

Propõe-se que o estudo seja replicado em maior horizonte de tempo para a situação de oligopólio para verificar se em prazos mais longos os resultados das estratégias emergentes tendem a se aproximar ou mesmo sobrepujar os resultados das estratégias planejadas.

Também se sugerem como novas pesquisas a ampliação da coleta de dados para maior número de rodadas e em diferentes níveis de concorrência, contemplando novas situações de concorrência monopolista e concorrência perfeita. É possível também desenhar um estudo comparando contextos de baixa oscilação e alta oscilação do ambiente, passível de operacionalização através dos indicadores macroeconômicos.

Outro estudo interessante do ponto de vista do processo decisório e do perfil do decisor, em curso no momento, consiste em se verificar a influência do perfil psicológico dos tomadores de decisão em relação aos resultados nas estratégias planejadas e emergentes. Este perfil pode ser 
Comparação da Geração de Valor entre as Estratégias Planejadas e as Estratégias Emergentes: Um Estudo Baseado em Jogos de Empresas

acessado através de testes do tipo MBTI (Myers-Briggs), analisando-se a complementariedade de distintos perfis psicológicos no processo de tomada de decisões mais efetivas, através da constituição de duplas e comparação das distâncias euclidianas dos perfis MBTI das duplas com seus resultados, em função das complementariedades cognitivas "intuição-razão" das duplas formadas. Assim, poder-se-ia supor algumas proposições a serem investigadas, como por exemplo: (a) melhores resultados nas estratégias planejadas para perfis predominantemente racionais, ou (b) melhores evoluções de resultados nas estratégias emergentes para perfis equilibrados entre intuitivos-racionais, ou seja, tanto maior o grau de complementaridade de perfis nos grupos, maior possibilidade de melhores estratégias emergentes.

\section{REFERÊNCIAS}

Abreu, M. C. T.; Masetto, M. T. O professor universitário em aula: prática e princípios teóricos. 8. ed. São Paulo: MG Editores Associados, 1990.

Chaffee, E. E. Three models of strategy. Academy of Management Review. v. 10, n. 1, p.89-98, 1985. doi:10.2307/258215

Chandler, A. D. Strategy and Structure: chapters in the history of the industrial enterprise. Cambridge, MA: MIT Press, 1962.

Cooper, P.; Mc Intyre, D. Effective teaching and learning: teacher's and students' perspectives. Buckingham: Open University Press, 1996.

Godoy, A.S; Cunha, M. A. V. C. cap.III: Ensino em pequenos grupos. In: Moreira, D. A. (org.) Didática do ensino superior: técnicas e tendências. São Paulo: Pioneira, 1997.

Godoy, A.S. cap.III: Revendo a aula expositiva, In: Moreira, D. A. (org.) Didática do ensino superior: técnicas e tendências. São Paulo: Pioneira, 1997.

Halpern, D. F. (and associates) Changing college classrooms: new teaching and learning strategies for an increasingly complex word. San Francisco: Jossey Bass, 1994.

Jaques, D. Learning in Groups. $2^{\text {nd }}$. ed. London: Kogan Page Limited, 1992.

Kolb, D.A. Experiential learning: experience as the source of learning and development New Jersey: Prentice-Hall Inc., 1984. 
Lakatos, E. M.; Marconi, M. A. Técnicas de pesquisa. São Paulo: Atlas, 1988.

MartinS, G. A. Manual para elaboração de monografias. São Paulo: Atlas, 1992.

Monteiro, M. F. O Currículo Universitário frente a mudanças na sociedade: análise da evolução do curso de Administração de Empresas em nível de graduação da FEA-USP. Administração Online, v.1, n.2, 2000.

Mintzberg, H.; Ahlstrand, B.; Lampel, J. Safári de estratégia: um roteiro pela selva do planejamento estratégico. Porto Alegre: Bookman, 1998.

Mintzberg, H. A Criação Artesanal da Estratégia. In: Montgomery, C.A.; M.E.

Mintzberg, H. The Rise and Fall of Strategic Plan. Hertfordshire: Prentice Hall, 1994.

Pereira, B. A. D.; Toni. D. D. A busca da racionalidade multidimensional da organização através da teoria da configuração. REAd - Revista Eletrônica de de Administração . Porto Alegre: ed. 29 vol. 8, n. 5, set-out 2002 .

Roglio, K. de D. Learning by sharing experiences: the development of reflective practice in executive MBA Programs. REAd - Revista Eletrônica de de Administração . Porto Alegre: ed. 53, vol. 12, n. 5, set-out 2006.

Sant'anna, F. M. Microensino e habilidades técnicas do professor. São Paulo: McGraw-Hill, 1979.

Sauaia, A. C. A. Laboratório de Gestão: simulador organizacional, jogo de empresas e pesquisa aplicada. 2a . Ed. Barueri: SP, Manole, 2010.

Sauaia, A. C. A. Gestão da Estratégia - um Guia Prático. Volume I - Grupo de Pesquisas Simulab FEA/USP. São Paulo, Março de 2006.

Sauaia, A. C. A. Jogos de empresas: aprendizagem com satisfação. Revista de Administração da Universidade de São Paulo. São Paulo: v.32, n.3, jul/set 1997.

Sauaia, A. C. A.; Kallás, D. Cooperar pelos lucros ou competir pelo mercado? O conflito do oligopólio tratado em um jogo de empresas. In: Anais do $28^{\circ}$ ENANPAD. Curitiba, 2004.

Tanabe, M. Jogos de empresas. São Paulo: Faculdade de Economia, Administração e Contabilidade, Universidade de São Paulo, 1977. Dissertação.

Weimer, M. Improving College Teaching-Strategies for Developing Instructional Effectiveness. San Francisco: Jossey Bass, 1990. 
Comparação da Geração de Valor entre as Estratégias Planejadas e as Estratégias Emergentes: Um Estudo Baseado em Jogos de Empresas

Zaccarelli, S. B. Estratégia e sucesso nas empresas. São Paulo: Saraiva, 2000.

Recebido: 01/02/2012

Aprovado: 27/03/2012

Revista Ibero-Americana de Estratégia - RIAE, São Paulo, v. 11, n. 1, p. 152-177, jan./abr. 2012. 